\title{
Use of Evaporative Water Cooling (EWC) in Grinding Chili
}

\author{
D. M. S. P. Bandara, K. S. P. Amarathunga, B. M. K. S. Thilakaratne, \\ C. R. Gunawardana, T. M. R. Dissanayake, D. A. N. Dharmasena and
}

A. J. Fernando

\begin{abstract}
Size reduction is one of the steps in processes where the raw materials are converted into final products. When considering spices, size reduction must be performed carefully because of the loss of aroma due to temperature increase during milling. These problems are encountered with conventional grinding of chili. Therefore, grinding under reduced temperature by means of water vapor was tested as a novel application. A pin mill with $5 \mathrm{hp}$ motor was used to grind chili with water mixing during milling in which water is considered as the coolant. The temperature of the conventionally ground and evaporative water cooled ground chili were $58 \pm 2.65{ }^{\circ} \mathrm{C}$ and $36 \pm 1.5^{\circ} \mathrm{C}$ respectively and the corresponding amounts of heat removed by water vapor were $29.33 \mathrm{~kJ}$ and 186.50 $\mathrm{kJ}$. The moisture content of conventionally ground chili and evaporative water cooled ground chili with water spraying were $9.06 \pm 0.41$ and $9.65 \pm 0.23$ percent on wet basis and the corresponding color values were $49.19 \pm 0.99\left(\mathrm{~L}^{*}\right), 17.35 \pm 1.62\left(\mathrm{a}^{*}\right), 23.38 \pm 1.29\left(\mathrm{~b}^{*}\right)$ and $47.52 \pm 1.74\left(\mathrm{~L}^{*}\right), 18.38 \pm 0.14\left(\mathrm{a}^{*}\right)$, $26.93 \pm 0.68\left(b^{*}\right)$. Retention of capsicum oleoresin in two grinding methods; conventional and EWC are $0.0217 \pm 1.27$ and $0.0129 \pm 1.00 \mathrm{mg} / \mathrm{ml}$ respectively. The results proved that the use of water vapor is applicable as the coolant in size reduction confirming reducing temperature rise during grinding, controlling the color weakening after grinding, preferable final moisture content with higher oleoresin retention than that of conventional grinding.
\end{abstract}

Keywords: Chili, Cryogenic grinding, Spice

\section{Introduction}

Processing and trade of spices have always been an important industry. The spice trade still has a significant impact on the economy of many countries such as Grenada, Sri Lanka and Indonesia. Spices are used in the preparation of food for many reasons such as enhancing the flavor and aroma of food, adding piquancy and pungency and improving appearance by adding color to food. These spices are also used in medicine because of their carminative, stimulating and digestive properties [8]. Chili (Capsicum annuиm L.) is a spice important in human food and a fruit vegetable widely cultivated in the world [2]. Throughout the world, chili is consumed fresh, dried or in powder form[3].

The main aim of spice grinding is to obtain smaller particle size with good product quality in terms of flavor and color. In the normal grinding process, heat is generated when energy is used to fracture particles into smaller sizes [5]. Power consumption in grinding, size of particles and increase in the surface area depends on the initial size, shape and strength of the particle or material; the kind of grinder or mill used for the operation and the fixing of operating parameters for running the grinder or mill such as temperature, size of sieve, number of rotor ribs etc.. [1].

Grinding is one of the most power consuming operations because only $1 \%$ of the energy imparted into the material is utilized for loosening the bond between particles, whereas

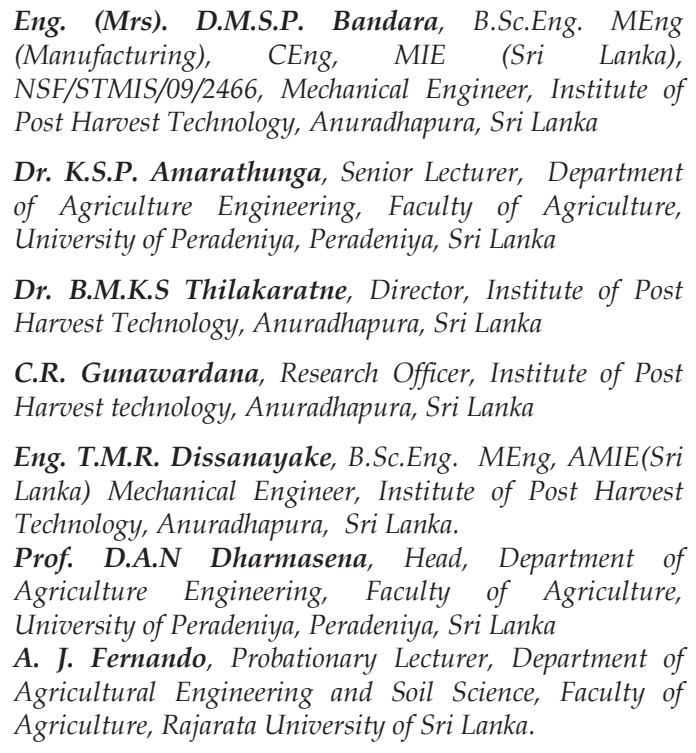

Dr. K.S.P. Amarathunga, Senior Lecturer, Department of Agriculture Engineering, Faculty of Agriculture, University of Peradeniya, Peradeniya, Sri Lanka

Dr. B.M.K.S Thilakaratne, Director, Institute of Post Harvest Technology, Anuradhapura, Sri Lanka

C.R. Gunawardana, Research Officer, Institute of Post Harvest technology, Anuradhapura, Sri Lanka

Eng. T.M.R. Dissanayake, B.Sc.Eng. MEng, AMIE(Sri Lanka) Mechanical Engineer, Institute of Post Harvest Technology, Anuradhapura, Sri Lanka.

Prof. D.A.N Dharmasena, Head, Department of Agriculture Engineering, Faculty of Agriculture, University of Peradeniya, Peradeniya, Sri Lanka

A. J. Fernando, Probationary Lecturer, Department of Agricultural Engineering and Soil Science, Faculty of Agriculture, Rajarata University of Sri Lanka. 
almost $99 \%$ of input energy is dissipated as heat, causing rise in the temperature of the ground product. Thermal damage is one of the main limitations of conventional grinding processes, and therefore it is especially important to perform grinding under controlled temperature conditions [5].

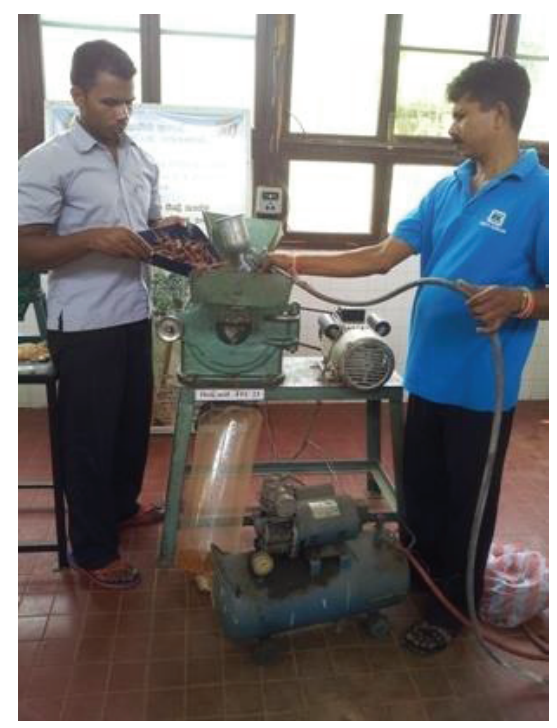

Figure 1 - Machinery set up for atomized water spraying during grinding

Calculation of temperature and its effect on thermal damage to the material undergoing grinding has been carried out by Malkin and Guo [5] and suggest that if the temperature of two rubbing surfaces is reduced, a better product could be obtained.

Normal grinding produces powder of poor quality that does not conform to the international quality standards and as a result either fetches lower prices or not accepted by the importing countries. The temperature rise of the product can be minimized to some extent by circling cold air or water around the grinder. But this technique is not sufficient enough to reduce the temperature rise of the product significantly. Loss of volatile matter can be significantly reduced by the cryogenic grinding technique using liquid nitrogen or liquid carbon dioxide that provides the refrigeration needed to pre-cool the spices and maintain the desired low temperature by absorbing heat generated during grinding operation [10].

In this study, one of the present popular types of grinding mills was subjected to adding water spray system during milling in which water is considered to be the one with the highest latent heat among the other substances, therefore it is to be tested as the coolant. The aim of this experiment is to use the advantage of high latent heat of water which could be used for absorbing energy dissipated during size reduction and thereby preserving the quality of product through this application.

\section{Methodology}

A homogeneous bulk sample of sun dried chili with moisture content of $11.25 \pm 0.5 \%$ on wet basis ( $\mathrm{wb}$ ) was used for the experiment. . A disk mill (model UD-23,) obtained from Udaya Industries, Weligalle and installed at Institute of Postharvest Technology, Anuradhapura, consisting of a rotating disk having diameter of $230 \mathrm{~mm}$ and $4 \mathrm{~kW}$ single phase motor was used for milling chili. A 500 micron sieve was selected to obtain the required particle size recommended by Sri Lanka Standards Institute, [11]. A spray gun (model of DCS-142, Iwata, USA), and a compressor $(0.2 \mathrm{~kW}$ and $1,440 \mathrm{rpm})$ was used to spray water at ambient temperature $\left(28^{\circ} \mathrm{C}\right)$ as the coolant. Water was sprayed at a rate of $1.1 \mathrm{ml} / \mathrm{sec}$ on chili fed to the mill at a rate of $30 \mathrm{~kg} / \mathrm{h}$ and the amount of water sprayed was maintained at $70 \mathrm{ml}$ per each run. The schematic diagram of the experimental setup of grinding chili with evaporative water cooling is shown in figure 2 .

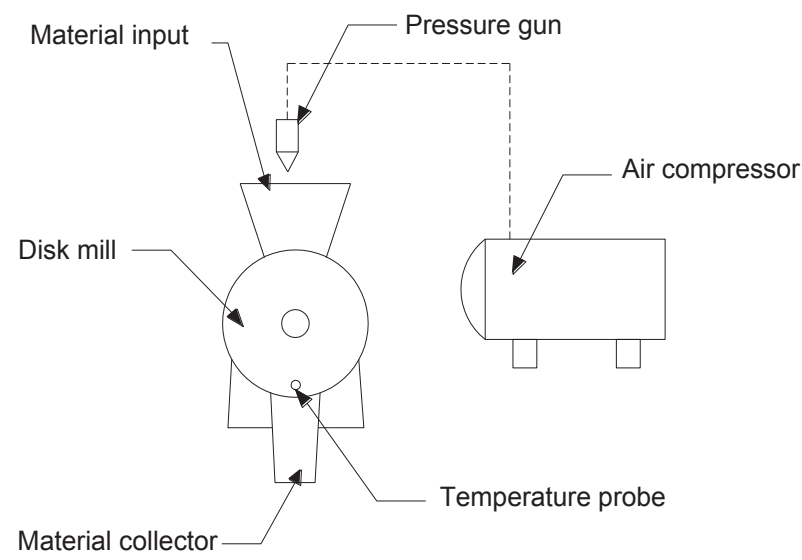

Figure 2 - The schematic diagram of the experimental setup of grinding chili with evaporative cooling

To measure the amount of capsicum oleoresins in ground product, Soxlet extraction was used (Figure 3). This extraction was made with the same ratio of solid-liquid phase (0.2:25). In order to assure the appropriate volume of solvent for Soxlet apparatus, $5 \mathrm{~g}$ of grounded chili had to be taken in $100 \mathrm{ml} 96 \%$ ethanol. The 
extraction was performed in 5 hours at a temperature of $80-85^{\circ} \mathrm{C}$ (ethanol boiling point is $78^{\circ} \mathrm{C}$ ). Final extracts were also diluted in ratio $1: 25[4]$.

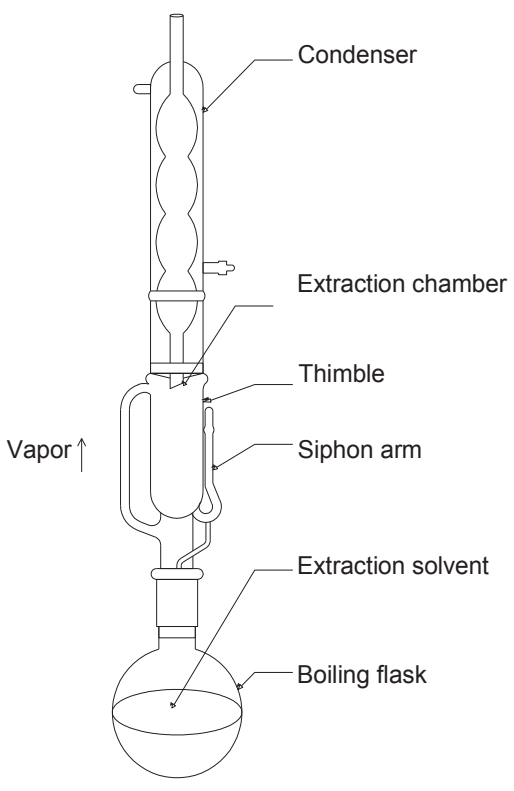

Figure 3 - Soxlet apparatus for oleores extraction

The temperature of the ground chili with evaporative cooling and conventionally ground chili were measured at the outlet of the mill using a digital thermometer (TECPEL, Model: 318) of accuracy $\pm 0.1{ }^{\circ} \mathrm{C}$. The color $\left(\mathrm{L}^{*} \mathrm{a}^{*} \mathrm{~b}^{*}\right)$ was measured by Chroma meter (Konica Minolta, Model CR-400). Color measurements were performed using five replicates. According to the AOAC method, Dean and Stark apparatus was used to measure the moisture content of the ground chili. Extracted moisture volume was measured using a measuring cylinder. Then moisture content was calculated by the equation 1.

$$
M c=\frac{W v \times D w}{S w} \times 100
$$

Where,

Mc - Moisture content \% w.b. ,

Wv - Water volume (ml),

$D w$ - Density of water $(\mathrm{g} / \mathrm{ml})$

$S w$-Sample weight $(\mathrm{g})$

The results were reported as the mean value \pm standard deviation. The data were subjected to analysis of variance using SAS by complete randomized design. Duncan's multiple range test was applied to determine significant differences at the $5 \%$ level of significance $(p<0.05)$.

\section{Results and discussion}

The initial color of chili pods obtained for study was $33.33\left(\mathrm{~L}^{*}\right), 21.26\left(\mathrm{a}^{*}\right)$ and $14.58\left(\mathrm{~b}^{*}\right)$. The ground samples with evaporative water cooling were compared with conventionally ground samples in terms of temperature rise during milling, final moisture content and color.

Table 1 shows the properties of ground chili by conventional and evaporative water cooled (EWC) grinding. The temperature of the ground chili by conventionally and evaporative water cooling with spraying water were $58 \pm 2.65$ and $36 \pm 1.5^{\circ} \mathrm{C}$ respectively. The statistical analysis demonstrated a significant difference in temperatures.

The moisture content of ground chili samples by conventional and EWC grinding were $9.06 \pm$ 0.41 and $9.65 \pm 0.23 \%(w b)$ (Table 1$)$.

The obtained moisture content values in both grinding method complied with the values specified by the Sri Lanka Standards Institute [11].

The color values of ground chili samples in

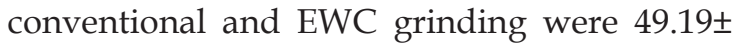
$0.99\left(\mathrm{~L}^{*}\right), 17.35 \pm 1.62\left(\mathrm{a}^{*}\right), 23.38 \pm 1.00\left(\mathrm{~b}^{*}\right)$ and $47.52 \pm 1.74\left(\mathrm{~L}^{*}\right), 18.38 \pm 0.14\left(\mathrm{a}^{*}\right), 26.93 \pm 0.68\left(\mathrm{~b}^{*}\right)$ respectively (Table 1). The lightness value was reduced in EWC ground chili with water spraying. Redness and yellowness values were higher in EWC grinding than the conventional grinding. According to Minquez-Mosquera [7], color of ground chili is the principal criterion for assessing its quality and value. This color results show higher darkness in EWC grinding than conventional grinding.

When evaluating the retention of capsicum oleoresin in two grinding methods, it was found that higher amount of concentration was recovered by the method of EWC grinding than that of conventional grinding. The amounts recorded in conventional and EWC are $0.0217 \pm 1.27$ and $0.0129 \pm 1.00 \mathrm{mg} / \mathrm{ml}$ respectively. Our results show that reducing temperature during grinding using water vapor can have an impact on preservation quality of ground chili. 
Table 1 - Properties of ground chili by conventional and EWC grinding with water spraying

\begin{tabular}{lrrr}
\hline Parameter & \multicolumn{1}{c}{$\begin{array}{c}\text { Conventional } \\
\text { grinding }\end{array}$} & EWC grinding \\
\hline Temperature $\left({ }^{\circ} \mathrm{C}\right)$ & $58^{\mathrm{a}} \pm 2.65$ & $36^{\mathrm{b}} \pm 1.5$ \\
Moisture content $(\%, \mathrm{wb})$ & $9.06^{\mathrm{a}} \pm 0.41$ & $9.65^{\mathrm{a}} \pm 0.23$ \\
& $\mathrm{~L}^{*}$ & $49.19^{* \mathrm{a}} \pm 0.99$ & $47.52^{\star_{\mathrm{a}}} \pm 1.74$ \\
Color & $\mathrm{a}^{*}$ & $17.35^{\star \mathrm{a}} \pm 1.62$ & $18.38^{\star_{\mathrm{a}}} \pm 0.14$ \\
& $\mathrm{~b}^{*}$ & $23.38^{* \mathrm{~b}} \pm 1.00$ & $26.93^{*_{\mathrm{a}}} \pm 0.68$ \\
$\begin{array}{l}\text { Capsicum oleoresin } \\
\text { concentration }(\mathrm{mg} / \mathrm{ml})\end{array}$ & & $0.0217^{\mathrm{a}} \pm 1.27$ & $0.0129^{\mathrm{a}} \pm 1.00$ \\
\hline
\end{tabular}

* Different superscript letters differ significantly according to Duncan's multiple range test $(p<0.05)$.

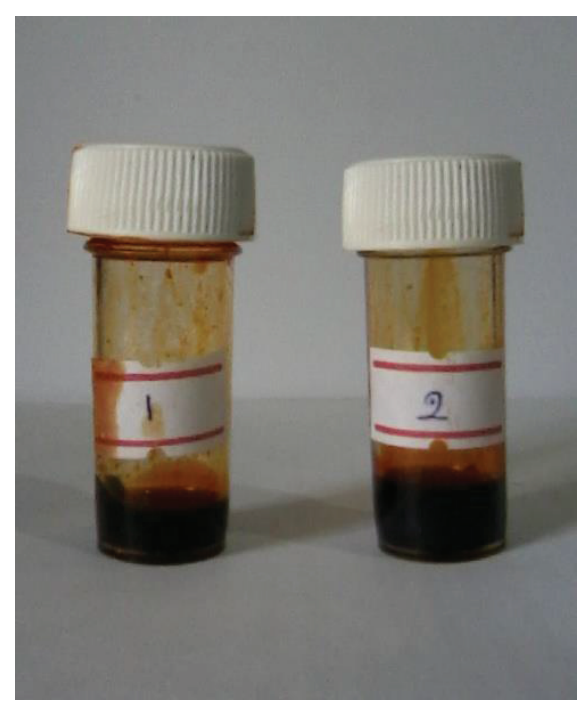

Figure 4 - Extracted oleoresin from both conventional (sample 1) and EWC method (sample 2)

Heat generated in size reduction was steered to increase the temperature of chili product in conventional grinding while heat generated was reduced in EWC grinding due to the sprayed water vapor as sensible and latent heat during grinding. In this study, the heat load absorbed by water was considered and sensible heat of water vapor was assumed as negligible in comparison to the latent heat of water. To calculate the latent heat of water vaporization, the following energy balance equation [12] was used. ' $\mathbf{m}$ ' is the mass of water and ' $\lambda$ ' is the latent heat of water (2365 $\mathrm{kJ} / \mathrm{kg}$ at $\left.58^{\circ} \mathrm{C}\right)$.

$Q=m \lambda$

The moisture removal was calculated by using the values of initial moisture content of chili pods and final moisture content of ground chili. The amount of moisture removed in conventional grinding was $12.04 \mathrm{~g}$. Therefore, the latent heat absorbed by moisture in chili at conventional grinding was $29.33 \mathrm{~kJ}$. The amount of water sprayed in EWC grinding was $70 \mathrm{~g}$. The amount of moisture removed in EWC grinding was $78.86 \mathrm{~g}$. The calculated latent heat at EWC grinding was $186.50 \mathrm{~kJ}$. In both grinding methods, the sensible heat absorbed by chili pods during grinding is negligible compared to the latent heat capacity of vaporized water.

\section{Conclusion}

Evaporative water cooling (EWC) method reduces the grinding temperature from $58 \pm$ 2.65 to $36 \pm 1.5{ }^{\circ} \mathrm{C}$ thus atomized water works as a coolant in chili grinding. The obtained results indicated that $186.50 \mathrm{~kJ}$ of heat was removed from the ground product treated by evaporative water cooling than conventionally ground product due to the addition of atomized water in EWC grinding. The ground 
chili obtained from EWC achieves a comparable moisture content with conventional ground chili. And the results for color value and the oleoresin retention of the final product proved that the quality grinding is obtainable using EWC grinding in comparison with conventional grinding. Therefore it could be concluded that evaporative water cooling for grinding chili could be effectively used as a low temperature size reduction method. Further studies are needed to be carried out for investigating the quantitative water amount to be sprayed and method of water application within a restricted environment. However, this study will be a guide to further examination of use of water vapor as the coolant for spice grinding industry to reduce the temperature rise during grinding.

\section{References}

1. Das, P., \& Sharma S. K., "Drying of Ginger using Solar Cabinet Dryer.", J. Food Science \& Technology, 38, 2001, pp 619-621.

2. Dias, G. B., Gomes, V. M., Moraes, T. M., Zottich, U. P., Rabelo, G. R., Carvalho, A. O., Moulin, M., Gonçalves, L. S., Rodrigues, R., Da Cunha, M. "Characterization of Capsicum species using Anatomical and Molecular Data, Genetics" and Molecular Research 12 (4): ,2013,pp. 6488-6501.

3. El-Ghoraba, A. H., Javedb, Q., Anjumb, F. M., Hamedc, S. F., Shaabana, H. A., Pakistani, "Bell Pepper (Capsicum annum L.): "Chemical Compositions and its Antioxidant Activity". International Journal of Food Properties, 16(1):1, 2013, pp. 8-32.

4. Koleva, G. Liljana*, maksimova viktorija**, serafimovska d. Marija **, gulabovski rubin", ivanovska j. Emilija** "The Effect of Different Methods of Extractions of Capsaicin on its Content in the Capsicum Oleoresins" Food Science, Engineering and Technology 2013“ pp 18-19.

5. Malkin, S. \& Guo, C., Thermal Analysis of Grinding. Annals of the CIRP Vol. 56 (2), Connecticut, USA. 2007.
6. Meghwal, M. and Goswami, T. K., (2010), "Cryogenic Grinding of Spices is a Novel Approach whereas Ambent Grinding needs Improvement", J. of Food science and technology, 4 pp 24-37.

7. Minquez- Mosquera, M. I., Jaren- Galan, M., \& Garrido- Fernandez, J., "Color Quality in Paprika". Journal of Agricultural Food Chemistry, 1992, 40: 2384.

8. Schweiggert, U., Carle, R., and Schieber, A., "Conventional and Alternative Process for Spice Production -Review", Trends in Food Science 2007, pp 260-268.

9. Singh, K. K., \& Goswami, T. K., (1997). "Studies on Cryogenic Grinding of Spices". IIT Kharagpur(India).

10. Singh, K. K., \& Goswami, T. K., “Studies on Cryogenic Grinding System for Spices", J. of Food Engineering, 39, 1999, pp 359-366.

11. Sri Lanka Standard Institution, Speciation for ground chilies (First Revision), (117:1988), 1988.

12. Verma, R. C., and Jain, S. K.)Fundamental of Food Engineering. Himansu Publications, Udaipur, New Delhi, 2002. 
